\title{
Safety, tolerability and feasibility of adenosine stress CMR in high-risk patients
}

\author{
Amardeep Ghosh Dastidar*, Alexander Carpenter, Catherine R Wilson, Nauman Ahmed, Chris B Lawton, \\ Mark Hamilton, Chiara Bucciarelli-Ducci \\ From 18th Annual SCMR Scientific Sessions \\ Nice, France. 4-7 February 2015
}

\section{Background}

Adenosine stress cardiovascular magnetic resonance (CMR) provides effective cardiac prognostication in patients with suspected coronary artery disease. However its use has been limited in high-risk patients and some reservations exist about offering adenosine stress CMR in patients with significant aortic stenosis, asthma, severe left ventricular (LV) systolic dysfunction, significant left main stem (LMS) disease and age $>80$ years.

\section{Aims}

To determine the safety, tolerability and feasibility of stress $\mathrm{CMR}$, in the diagnosis of inducible myocardial ischaemia in high-risk individuals as compared to non-high risk.

\section{Methods}

From April 2013-February 2014, 542 consecutive adenosine stress-CMR examinations were performed. Cardiovascular and symptomatic response to adenosine stress was recorded in every patient. The CMR protocol included cine (long and short axis), stress and rest firstpass perfusion imaging, and late gadolinium enhancement (LGE) imaging. Patients were classed as high-risk if any of the following criteria were fulfilled: age $>80 \mathrm{yrs}$, asthma or chronic obstructive pulmonary disease (COPD), significant left main stem stenosis and moderate-severe or severe aortic stenosis or severe LV systolic dysfunction (ejection fraction $<40 \%$ ). Comparisons were made using the Fisher exact test for binary variables.

\section{Results}

542 consecutive stress-CMR were included in the analysis (mean age 64 years and $71 \%$ males), out of which 99 patients $(18 \%)$ met the criteria for high-risk. Overall,

\footnotetext{
NIHR Cardiovascular Biomedical Research Unit, Bristol Heart Institute, Bristol, UK
}

\section{Conclusions}

Adenosine stress-CMR is a safe, well-tolerated and feasible investigational modality in high-risk individuals (moderate/severe aortic stenosis, significant LMS stenosis, severe LV systolic dysfunction, asthma/COPD or age $>80$ ) with suspected ischaemic heart disease. The incidence of myocardial ischemia or LGE is significantly higher in the high-risk group.

\section{Funding}

This study was funded by the National Institute for Health Research Biomedical Research Unit in Cardiovascular

Table 1

\begin{tabular}{ccccc}
\hline & $\begin{array}{c}\text { Total } \\
(542)\end{array}$ & $\begin{array}{c}\text { High-risk } \\
(99)\end{array}$ & $\begin{array}{c}\text { Non-high risk } \\
(443)\end{array}$ & P-value \\
\hline Male (\%) & $387(71.4)$ & $70(70.7)$ & $317(71.6)$ & 0.90 \\
\hline $\begin{array}{c}\text { Stress } \\
\text { response }\end{array}$ & 535 & 97 & 438 & 0.62 \\
\hline Drop out & 35 & 1 & 34 & 0.01 \\
\hline Ischaemia & 234 & 62 & 172 & 0.0003 \\
\hline LGE & 295 & 73 & 222 & $<0.0001$ \\
\hline
\end{tabular}


Disease at the University Hospitals Bristol NHS Foundation Trust and the University of Bristol.

Published: 3 February 2015

doi:10.1186/1532-429X-17-S1-P124

Cite this article as: Dastidar et al: Safety, tolerability and feasibility of adenosine stress CMR in high-risk patients. Journal of Cardiovascular Magnetic Resonance 2015 17(Suppl 1):P124.

Submit your next manuscript to BioMed Central and take full advantage of:

- Convenient online submission

- Thorough peer review

- No space constraints or color figure charges

- Immediate publication on acceptance

- Inclusion in PubMed, CAS, Scopus and Google Scholar

- Research which is freely available for redistribution

Submit your manuscript at www.biomedcentral.com/submit 